\title{
Sobre a Declaração Universal dos Direitos HUMANOS: NOTAS INICIAIS DE UM PSICANALISTA
}

\author{
Chaim Samuel Katz*
}

\section{Resumo}

A Declaração Universal dos Direitos Humanos se pretende com e de validade universal. Assim, se coloca como postulação que deve atingir quaisquer grupos e países, em todas as situações. A Psicanálise freudiana, atenta ao sombrio humano, mostra que a universalidade não se constitui unicamente de afirmaçóes conjuntivas. Os assujeitados e os agrupamentos são constituídos, sempre e sem exceção, também de modalidades disjuntivas e de vazios.

Palavras-chaves: Declaração Universal dos Direitos Humanos; Psicanálise freudiana.

\section{Abstract \\ About the Universal Declaration of Human Rights: Preliminary notes of a PSYCHOANALYST \\ The Universal Declaration of Human Rights is intended to have universal validity, putting itself as true to all groups and countries, in every situation. Freudian Psychoanalysis, however, concerned about human darkness, shows that human subjects and groups are formed, always and without exception, of disconnections and emptiness. \\ Keywords: Universal Declaration of Human Rights; freudian psychoanalysis.}

Se tomamos os trinta itens da Declaração Universal dos Direitos Humanos (DUDH), estabelecida em 1948 pela Organização das Nações Unidas (ONU) em São Francisco, Califórnia, nos Estados Unidos, e os cotejamos com o que sabemos acerca das relaçóes internacionais tais como se apresentam no quotidiano "do

* Psicanalista; Membro da Formação Freudiana; Doutor em Comunicação pela Universidade Federal do Rio de Janeiro (UFRJ). 
mundo" e também na contemporaneidade civil e política brasileira, eles se apresentam como postulação bastante esvaziada enquanto regime universal, o que não impedirá pensar suas afirmações. Ao mesmo tempo, sabemos que se trata de um conjunto de afirmaçôes acerca de temas muito complexos, que se supõem como ideais a serem atingidos e que conseguiram a aprovação da maioria dos países que então constituíam a ONU. Ainda hoje, eles nos suscitam pensamentos que emergem desde "nosso" modo ocidental de ser (o que quer que isto seja; mas eu o indico adiante). Contudo, mesmo na época, se quarenta e oito países a aprovaram, outros oito se abstiveram de fazê-lo (União Soviética, Rússia Branca, Checoslováquia, Iugoslávia, Ucrânia, Polônia, Arábia Saudita e África do Sul; os primeiros quatro desses países já nem existem mais e o último se transformou radicalmente), pois não teria tal característica de universalidade atribuída e desejada então.

Já em 2007, a 62a sessão da Assembléia Geral da ONU reuniu cento e noventa e dois países, um número quase quatro vezes maior do que a de 1948, cujas divisões, cisōes internas e reorganizaçōes geográficas, étnicas e políticas ainda se fazem atualmente. Neste mesmo ano, o primeiro ministro de Portugal renovou as questôes postas em 1948: "Se há ensinamento que a passagem para o século XXI nos trouxe foi o de que os desafios globais exigem respostas globais, e exigem um multilateralismo efetivo, que se joga aqui, nas Nações Unidas e com as Nações Unidas" ${ }^{1}$, afirmou José Sócrates. Esta variação é bem diferente do discurso universalizante da DUDH “original”, já que postulou o combate ao terrorismo, a retirada dos aliados ocidentais (comandados pelos Estados Unidos) do Iraque e pediu a abolição da pena de morte. Além do mais, José Sócrates, que presidia então o Conselho Europeu, se dedicou a pensar a autonomia de Kosovo, a consolidação política e a integração do Timor Leste e pregou a luta contra a pobreza. Sem falar que ele se referiu à necessidade de ampliar a luta ambiental que, junto com as questôes das imigraçōes e dos preços do petróleo e dos alimentos, são os temas políticos imediatos-mediatos e de maior importância neste novo milênio.

Naquele mesmo ano de 1948, depois de uma guerra, fundou-se o Estado de Israel, apoiado pelas duas então Grandes Potências (os Estados Unidos e a União Soviética), com o domínio político, econômico e militar dos judeus. Esta fundação se fez na base de forças afirmativas específicas e, diante dos eventos da Segunda Guerra, também necessária à sobrevivência física dos judeus. Mas, como todo evento histórico fundador, este deixou um resto insanável, a questão da Palestina e dos palestinos.

Muitos países se criavam e se afirmavam bem longe de suas "fundações" históricas e políticas habituais e os Direitos Humanos foram se transformando. 
Três anos depois da fundação da Organização das Naçôes Unidas, quase 20\% dos países que nela estavam representados já não se entendiam acerca do que eram ou deveriam ser "direitos humanos". Ou seja, devemos pensar não apenas a questão da universalidade dos DUDH, de sua afirmação acerca de (um pretenso) O Homem, mas ver por que as questôes que caracterizaram ou deveriam caracterizar politicamente e intersubjetivamente os países tanto se modificaram e continuam a se transformar. Mas continuam "esperando" questionamentos!

\section{Ser HUMANo}

Foucault ([1966] 1994) nos ensinou que o que conhecemos como Humanismo emerge apenas desde o século XIX. Nos séculos XVI, XVII e XVIII e, diferentemente do que se aprende academicamente, "o homem não tem literalmente nenhum lugar. A cultura é então ocupada por Deus, pela semelhança das coisas, pelas leis do espaço, certamente também pelos corpos, pelas paixões, pela imaginação. Mas o próprio homem está inteiramente ausente" (Foucault, [1966] 1994: 540).

O Homem, esta figura em torno da qual se elaboraram os trinta itens da Declaração de 1948, seria uma figura produzida pelos conhecimentos sobre o que se entendia na época como seres humanos, e não estatuído numa base moral universal que o antecedesse. $\mathrm{O}$ que denominamos Homem emerge desde a convergência de discursividades; portanto, inexistiria o que alguns filósofos denominam de "natureza humana". Eu acrescentaria, apenas, que tal figura se constrói também em torno de interesses que lhe atribuem um conjunto de práticas morais, que se manifestam como um ideário unitário e seu conseqüente devir.

Tomando a questão dominante de um Deus monoteísta anterior, criou-se uma espécie ocidentalizada de $\mathrm{O}$ Homem, ser uno e unitário de origem divina e que se caracterizaria antropologicamente (como que para confirmar a teorização de Ludwig Feuerbach - 1874-1872 - de que Deus é uma criação dos ditos humanos $)^{2}$. Contudo, não se deve pensar o tema ou erigir alguma questão de modo relativista. Não basta afirmar que se trata de itens "ocidentais", valores que o Ocidente (ou os grupos pensantes e politicamente mais fortes ocidentais) insistiu em apresentar como verdade e partícipe de A Verdade, e que nem sempre serviram como metas, alvos (Zielen) para outros grupos sociais, países e povos fora do interesse e do alcance do fazer e das manifestações de poder ocidentalizantes. Apesar de saber, conforme indico adiante, que a questão do que são direitos humanos depende também de quem ou de quens a enunciam, mesmo nos grandes agrupamentos "morais" do Ocidente. 


\section{E NÃO SER HUMANO}

Se não temos espaço para considerar o que acontece efetivamente com inúmeros grupos que existem no interior das várias culturas, será preciso pensar o que são tais outros conjuntos (que só existem por exclusão), a quem nem se dá mesmo o direito de sobreviver; países de expatriados. A tal fenômeno, o filósofo e pensador jurídico italiano Giorgio Agamben (2004) mostrou como eles se assujeitam ao estado de exceção. Como ele ensina, resumidamente, em uma entrevista:

A significação profunda do estado de exceção como uma estrutura original, pela qual o Direito inclui em si o [ser] vivo por meio de sua própria suspensão, se revelou em toda a sua clareza com a military order que o presidente dos Estados Unidos [George W. Bush] decretou em 13 de novembro de 2001. Tratava-se de submeter os não-cidadãos [dos EUA] suspeitos de atividades terroristas a jurisdiçōes especiais, que incluíam sua detenção ilimitada (indefinite detention) e sua transferência ao controle de comissōes militares. O USA Patriot Act de 26 de outubro de 2001 já autorizava o attorney general [procurador-geral da República] a deter todo estrangeiro (alien) suspeito de pôr em perigo a segurança nacional. Era preciso, porém, que em sete dias esse estrangeiro fosse expulso - ou então acusado de ter violado a lei de imigração ou cometido outro delito. A novidade da ordem do presidente Bush foi apagar radicalmente o estatuto jurídico desses indivíduos e de produzir assim entidades que o Direito não podia nem classificar nem nomear. Não apenas os talebãs capturados no Afeganistão não podem gozar do estatuto de prisioneiros de guerra pela Convenção de Genebra, mas também não correspondem a nenhum caso de imputação fixado pelas leis americanas: nem prisioneiros nem acusados, mas simples detainees (detidos), eles se acham submetidos a uma pura soberania de fato, a uma detenção que não é apenas indefinida num sentido temporal, mas também por sua própria natureza, pois ela escapa completamente à lei sob toda forma de controle judiciário. Como detainee de Guantánamo, a vida nua atinge sua indeterminação mais extrema (Agamben, 2003: 14).

Tal conceito concreto de "vida nua", que Agamben desenvolveu desde o que (na contemporaneidade) Walter Benjamin denominou de "mera vida" (blosess Leben), é a vida civil nua e crua a ser exposta aos e desde aparelhos institucionais, jurídicos, culturais e políticos e está determinada desde um conjunto de Leis que muda de acordo com interesses dominantes, momentâneos ou não, devendo-se à violência imediata e afirmativa, que recusa quaisquer pretensōes aos direitos univer- 
sais, mas os inaugura. Trata-se de uma "categoria", o homo sacer, que pode ser eliminada, posta fora e excluída das categorias do Direito, pois não se assujeita pelas e desde as leis que preservam a vida como bem.

Carl Schmitt (1888-1985), o maior pensador jurídico do Terceiro Reich alemão, insistiu que caberia ao poder soberano decidir sobre quem deve ser excluído dos direitos constitucionais, bem como seria tarefa do que se denomina de poder soberano a escolha do momento adequado e dos motivos para fazê-lo. Ou seja, mesmo que tivermos que pensar algum regime universal e universalizante que constituísse a fonte dos Direitos, temos elementos que nos obrigam a elaborálos distintamente do modo habitual, eurocêntrico, pois são ou deveriam ser, também e doravante, leis a serem cumpridas. Mas elas fabricam simultaneamente suas exceções, pois não atingem a "todos" do mesmo modo, como mostra o exemplo pungente do homo sacer: a vida nua abrange um enorme número de pessoas e tem uma relação bem estabelecida (mesmo que variável) com os regimes de Soberania. A chamada vida nua não decide sobre o que ela própria é ou o que vale, seus valores devêm de interesses poderosos que a autorizam, ou não (o que não implica em não-aceitação e não-reação dos excluídos, conforme sabemos).

\section{Outras DECLARAÇÕES}

Simultaneamente, entram em ação diversas outras ordens de DUDH, muitas vezes com características de paródia, pois se estabelecem longe das decisões advindas desde a Soberania, ou seja, desde amplos poderes soberanos. Em abril de 1980, num modo ocidentalizante, organizou-se em Londres uma Conferência sobre "Direitos Humanos Muçulmanos". Dirigida e organizada por um grupo denominado Islamic Human Rights, sob a égide do profeta Muhammad (mais conhecido entre nós como Maomé), postulava que tais Direitos provinham diretamente de Állah e que, por isto, não podiam ser violados. Como Deus (ainda) não fala diretamente com (quase) ninguém, e esse grupo dirigente muçulmano mora, habita, vive e se exerce no Ocidente (por isto, tendo que contentar muçulmanos em geral e simultaneamente os poderes soberanos dos países onde habita), afirma que, apesar de postular que "é nossa obrigação estabelecer uma ordem islâmica", para isto deve existir uma vida social "onde todos os seres humanos sejam iguais e que ninguém goze de privilégios ou sofra prejuízo ou discriminação em razão de raça, cor, sexo, origem ou língua; onde todos os seres humanos nasçam livres". Sem, contudo, mostrar que a escravidão é reconhecida como tal em inúmeros países islamitas e que os direitos das mulheres, das crianças e das mi- 
norias são ali, enquanto tematizações de um estado jurídico normatizado do tipo ocidental, profundamente restritos e desrespeitados.

Entrando no site da Anti-Slavery International, aprendem-se tais fatos de modo efetivo. Em todo o mundo, desde os países árabes até os da América Latina (incluindo o Brasil), existe o tráfico e a circulação de escravos, crianças e adultos, com finalidades sexuais e de trabalho, em número surpreendente. No Golfo Pérsico, os escravos, principalmente mulheres, se contam em cerca de 1.300 .000 , e as crianças são comercializadas pelos próprios pais para prestar trabalhos domésticos, nas casas de seus compradores, de cerca de vinte horas diárias. Nos Emirados Árabes, negociam-se crianças com menos de dez anos de idade para serem jóqueis de camelo, atividade perigosa mas profissionalmente valorizada. Na América Latina, avalia-se que há cerca de 1.400 .000 pessoas vivendo em regime de escravidão.

Mas conhecemos alguns outros diferenciais, marcantes, das postulações de tais "Direitos Humanos Muçulmanos". Como exemplo, inúmeras comunidades não-muçulmânicas no Irã são perseguidas e segregadas, obrigadas a usar distintivos que as marcam na aparência, desde seu vestir. A comunidade bahá'í, que é a maior minoria religiosa no Irã, conta com trezentos mil membros e existe desde a primeira metade do século XIX, com cerca de seis milhões de seguidores em inúmeros outros países. Contudo, mesmo proclamando que todas as religióes reveladas têm princípios sagrados similares, ao afirmar idealmente a unidade de direitos entre mulheres e homens, ao criticar francamente os preconceitos de uma crença sobre as outras, isto leva a que, no Irã contemporâneo dominado pelos xiitas, os seguidores baha'is sejam perseguidos e se tornem alvos permanentes de torturas e atentados. Pois eles não obedecem e nem seguem os dogmas xiitas, já que seu messias deverá advir como um superador dos messias anteriores e não como demiurgo Único.

Imaginem a situação dos judeus no Irã contemporâneo, um pequeno grupo de cerca de vinte e cinco mil seguidores (cerca de $0,028 \%$ da população), considerados inimigos definitivos dos muçulmanos governantes e, ainda mais, determinados desde uma produção imaginária coletiva (e politicamente incitada) como cidadãos do Estado de Israel, inimigo a ser exterminado fisicamente. Neste país de cerca de setenta milhões de habitantes, são obrigados a se vestir usando distintivos, uma insígnia específica (o zonar), telas de cor amarela que evidenciam que não apenas não são islâmicos como são judeus, para distingui-los dos iranianos "normais"; este distintivo, criado no século IX, foi imitado pela Alemanha nazista.

Ou seja, é difícil postular a existência de termos e deveres universais enquanto direitos reconhecidos nos/aos humanos em geral, na medida em que os huma- 
nos são bem diferentes entre si. Contudo, os termos da DUDH se afirmavam em um modo universal.

\section{UNIVERSALIDADE, UNIVERSALIDADES}

Pensarei alguns poucos pontos - considero que o texto de sessenta anos atrás nos é conhecido e foi, além disto, republicado nesta nossa edição. Elaboro aqui algum vocabulário e o pensamento freudianos, já que Freud ensinou que as metas dos investimentos pulsionais se miram desde sua afirmação a partir das experiências sensíveis, postas também como regimes de intensidades, seus impulsos pretendem uma expansão ilimitada, um impulso ou impulsão permanente, seguidos (a expansão) de um processo de regulação dos excessos pulsionais e que constituem objetos (por definição, inalcançáveis). A vida humana é uma expansão e divisão permanentes, é um encontro e convergência de corpos e incorporais, uma busca incessante de finalidades de realização prazerosa e felicidade plena, inalcançáveis. Inúmeras teorias psicanalíticas contemporâneas deixaram de considerar a animalidade do Humano e com isto abandonaram o significado dos corpos e seus afetos e emoções (que viriam unicamente desde O Desejo).

Ou seja, para os psicanalistas freudianos, se a DUDH é necessária, do mesmo modo que deve ser necessariamente e permanentemente corrigida, ela é por definição inalcançável enquanto conjunto a ser per-feito. Por que postular isto? Pois se estabeleceu entre os mais variados pensadores, com as devidas e honrosas exceçôes, que seriam duas e apenas duas correntes a interpretar tais postulações que organizam a DUDH, universalistas e relativistas. Mesmo que de modo indicativo, pensarei de maneira universalizante, mas a universalidade aqui procurada não se faz apenas de agrupamentos e conjunções previamente postulados; nem mesmo da busca e perseguição de um ideal ou conjunto de ideais a serem alcançados. Ou não se faz apenas com eles, pois vazios e disjunções também existem, são, se afirmam e insistem em qualquer organização de pensamento. $\mathrm{Na}$ verdade, experimento indicar ou mostrar como a Universalidade, por definição, não é universal no sentido de alguma completude.

\section{O SOMBRIO DO HUMANO}

Os Direitos Humanos têm uma razão que procura reuni-los, mas se unificam simultaneamente através de mecanismos de poderes e interesses que recusam sua unidade, pois a Razão emerge de várias partes e de diversos modos. Além disto, e principalmente, desde a teorização de Freud, apreendemos que o que 
entendemos como Razão se ilumina também desde o sombrio: as pulsões não seguem e nem tendem a ou se dirigem a uma única Razão universal. Da perspectiva do pensamento freudiano, tal unidade, real ou ideal, é constituída simultaneamente pela insistência de cortes, vazios, transgressōes, irrupções, diferenças excessivas, rupturas e descontinuidades, passagens violentas entre situações disjuntas etc. Para os psicanalistas freudianos, que se aproximam das teorias que pensaram as singularidades e suas afirmações, a variação do Ser (se é que ainda se pode falar de Um Ser) é permanente, mesmo quando possamos experimentar integrá-lo, pois ele se modifica de acordo com seus questionamentos. Então, é seguir para a frente, pois, como aprendi com Claudio Ulpiano, "colocar problemas é modificar o ser".

Se o grande pensamento do Ocidente acreditou que os conceitos matavam as coisas (Hegel), pois todo racional é real já que todo real é racional, e os eventos se encaminhariam para um fim que pode ser pensado como a via teleológica do Espírito Absoluto devindo História, nossa época nos ensinou, de modo vivo e mortífero, que o conceito não subsume os seres. Saber produz Razão, mas também o faz o não-saber. A chamada Razão não pode integrar o Mal, pois ela não é “o" Bem (na melhor das hipóteses, seria "um” Bem), suas modalidades de se fazer não caminham para um único centro de onde dimanasse o ordenamento dos seres. Estamos longe de um certo platonismo que considerava as três idéias fundamentais ou essenciais (O Bem, O Belo, O Justo) e sua realização como condição para a articulação política harmônica e equilibrada.

As dissensões constituem indissoluvelmente os caminhares e trajetórias e elas não se produzem de forma antitética, não se fazem enquanto contradições que se encaminham para uma síntese superior e superadora, nem se dirigem ou devêm para algum Espírito Absoluto que as constituísse subsumidamente ou no final de uma (grande) Jornada. Enquanto o conjunto das Declarações considera, implicitamente, uma noção de progresso, que adviria desde a superação de passagens provisórias que se mostrariam de acordo com seu conjunto, desde que elas se pudessem reconhecer verdadeiramente e ouvir Uma única voz que as enuncia ou deveria enunciá-las corretamente; ou seja, as diferenças se desfariam através de superações, com o progresso.

\section{DEVER-SER E É}

Acompanhemos alguns enunciados: "Todos os seres humanos nascem livres e iguais em dignidade e direitos [crianças nascem dependentes, sempre]. São dotados de razão e consciência e devem agir em relação uns aos outros [e os psicóticos, 
que produzem outra Humanidade ou Inumanidade?] com espírito de fraternidade.... [mas, o primeiro grande crime da Humanidade ocidental foi fraterno, Caim matou Abel]. Todo ser humano tem capacidade para gozar os direitos e as liberdades estabelecidos nesta Declaração [o que inclui as crianças...]. Não será também feita nenhuma distinção fundada na condição política, jurídica ou internacional do país ou território a que pertença uma pessoa, quer se trate de um território independente, sob tutela, sem governo próprio, quer sujeito a qualquer outra limitação de soberania... Todo ser humano tem direito à vida, à liberdade e à segurança pessoal... Ninguém será mantido em escravidão ou servidão... Ninguém será submetido à tortura nem a tratamento ou castigo cruel, desumano ou degradante... Todo ser humano tem o direito de ser, em todos os lugares, reconhecido como pessoa perante a lei" etc., etc. Afirmações que desconsideram os sistemas colonialistas (que se aprendem intensamente com Joseph Conrad ([1902] 2004) ou que não consideram Auschwitz e similares, ao menos.

Tal conjunto de performativos, que se dirige pela caracterização de Um Homem universal (e, conseqüentemente, universalizante), de onde dimanariam as regras morais e as Leis generalizantes, carece, contudo, da inclusão do dissenso e das dissimetrias. Pois estes últimos não estão em outra coisa, que devem ou deveriam performar necessariamente, pois cada qual se afirma per se, tem trajetória e organização específicas, regimes próprios de performatividade, eis do que se trata.

\section{Um pouquinho de Freud e de alguma Filosofia faz falta}

Quando Freud pretendeu fundar o estatuto do Inconsciente, mostrou como este se constituía de estratos diferenciados, e que a passagem de um estrato ao outro (da consciência para o inconsciente, por exemplo) provoca um sintoma, um algo específico irredutível, e não uma elaboração sintética e finalizada de uma inscrição pela outra. Se os produtos que emergem de tais inscrições diferenciadas tendem a fabricar lugares, específicos, distintos de um sistema antecedente, os sintomas são positividades, afirmações, e não simples derivados de um sistema pleno prévio (onde outras teorias postulavam uma dependência de um pleno original; por exemplo, na Psiquiatria tratava-se de eliminar ou apagar os sintomas, levá-los à "normalidade", e não de elaborá-los). A vida social, dizendo melhor, as vidas sociais se constituem de multiplicidades, de vazios, irrupçôes e afirmações desde inúmeras e infinitas perspectivas. Infinitas, mas sem um modelo prévio (eventos não têm modelo necessário, como se aprende com as quatro posições freudianas sobre a pulsão, que indiquei acima), pois vão se fabricando enquanto se produzem incessantemente de modos diferenciais. Naquilo que constitui con- 
cretamente a trajetória do fazer-se humano, não se trata de anular os termos, pois eles são conseqüências no real e não são, ou nem sempre são, inscritíveis logicamente. Uma tendência não se resolve dialeticamente na outra a fim de que constituam um Mesmo em movimento com uma finalidade definida (como se encontra no fulcro da obra profundamente importante de Hegel) ou que advenham de um Idêntico (algum Deus) que as originaria.

Conforme ensinava Kant: "Pode-se pensar que não exista um certo movimento, mas o que não se deixa pensar é que ele seja e não seja ao mesmo tempo" (Kant, [1763] 1966: 784; tradução nossa). Não tendo que chegar a um Espírito Absoluto que subsumisse conceitualmente conceitos e coisas, Kant não confundiu diferença lógica e diferença ontológica, e por isto mesmo propôs, para cada ordem, uma adequação específica. Nas determinações ontológicas não há oposição lógica, na medida em que um dos termos não contradiz o outro (o que acontece na determinação lógica): "O negativo do nascer (Aufgehen) é o perecer (Untergehen), mas isto não se entende [como que] um seja o negativo do outro, mas [como] algo distinto, que se encontra numa oposição real com o outro" (Kant, [1763] 1966: 788; tradução nossa).

Claro, os não-platônicos que já estudamos Heráclito somos críticos da noção de um tempo único e unitário, juízos sintéticos do tempo, uma espécie de esquema totalizador prévio e que obrigasse e abrigasse todos os eventos, um tempo que contivesse também toda a vida civil (como em Kant, [1763] 1966). Se consideramos o conceito de vida nua e crua (conforme indiquei acima), veremos que o tempo não é unitário, nem para os que, soberanamente, inventam e obrigam as ditas leis de exceção, menos ainda para os que a elas são obrigados a se submeter. Pensemos na categoria de tempo imediato das crianças pobres que não se preocupam com suas próprias mortes, pensamento brasileiro que desafia o conceito do Dasein heideggeriano como ser-para-a-morte. Mas, se nos detivermos nessa discussão tão necessária, não pensaremos a DUDH.

Os itens da Declaração têm uma correlação que precisa ser afirmada e meditada. Para pensar questões bem próximas, e que se tornam cada vez mais genéricas, onde há fome extrema não há possibilidade de escolher "adequadamente" candidatos nos sistemas democráticos; ou seja, a fome precisa ser satisfeita, ou morre o dono (ou assim nomeado dono) do voto. Os chamados eleitores votam também de acordo com suas necessidades e a sobrevivência mínima (suas e de seus próximos), a manutenção das pulsóes de vida e da integridade do corpo ainda está no topo de suas aspirações, bem como o desvalor da morte própria. Sem dúvida, existe o desejo de se submeter, mas ele se mescla com o chamado à extensão da vida. Se, como afirmava Confúcio, é preciso ensinar a pescar e não apenas dar o 
peixe aos necessitados, na chamada política da bolsa-família no Brasil se criou uma nova classe de eleitores e seu desejo é continuar a sobreviver e se expandir, comendo peixe, antes ou independentemente de poder pescar; do mesmo modo que os eventos brasileiros nos mostraram que os políticos se elegem com a primordial tarefa de pagarem os custos de investimentos nas suas eleições e acumularem bastante e, depois, bem depois, de atender aos chamados de seus eleitores. Conforme se aprende com o tão difamado Mikhail Bakunin (1814-1976), o ideal se faz para o que no indivíduo se dirige desde a sua expansão e não desde um suposto lugar social onde ele se gerou: cada qual é empurrado e impulsionado pulsionalmente pela expansão, os lugares sociais devêm.

\section{EXTENSŌES DAS DUDH}

O conceito atual de direitos humanos foi confirmado com a realização da Conferência Mundial sobre Direitos Humanos, ocorrida em Viena, em 1993. Naquela ocasião, foram elaborados a Declaração e o Programa de Ação. Em seu parágrafo quinto, tal outra Declaração estabelece que: "Todos os direitos humanos são universais, interdependentes e inter-relacionados. A comunidade internacional deve tratar os direitos humanos globalmente de forma justa e eqüitativa, em pé de igualdade e com a mesma ênfase". Lembremo-nos que o assim denominado Mundo saía de uma bipolaridade (entre Estados Unidos e URSS) para uma unipolaridade (EUA) e já apontando para a multipolaridade de políticas e interesses. Por exemplo, a então Checoslováquia ou Tcheco-Eslováquia, que desde 1948 era parte do domínio soviético (invadida pelos exércitos comunistas em 1968), separou-se da então URSS em 1989. Porém, pouco depois, ela própria se dividiu em dois países distintos, a República Tcheca e a Eslováquia; ambas pertencendo hoje à União Européia. Isto começou a preparar a afirmação da DUDH em um plano menos "universal" do que imaginam alguns regimes conjuntivos; isto é, com muitos centros afirmativos de soberania e não um único apenas.

Os brasileiros devem ou deveriam saber que já está em movimento uma partilha do território brasileiro da Amazônia, das mais ricas regiôes em riquezas ditas naturais. Para atender a interesses de grandes proprietários brasileiros e capitais internacionais, alguns novos países seriam criados, em nome da autonomia de povos indígenas e de intervenção de ONGs "desinteressadas". Do mesmo modo que a Bolívia dificilmente contemplará o final desta década sem se ver dividida (ao menos) em dois países bem distintos. Esta história de produção de novos países, das inúmeras partiçooses étnicas que se legalizam juridicamente no modo internacional, e que se podem antecipar, não faz parte dos itens da "Declaração", 
mas é o que ocorreu nestes últimos sessenta anos e continuará a acontecer, sem que nenhuma Declaração possa detê-la. Trata-se de uma perene reclamação e produção concreta de diferenças, muitas vezes em torno do que Freud denominou de "narcisismo das pequenas diferenças", mas que repousa em torno de interesses (inter-esse) e afirmações de poderes, que recusam a homogeneidade pós-moderna em torno da globalização (por mais que este processo se afirme e reafirme).

\section{MORAL, MORAIS}

Contudo, na linha de pensar a DUDH como necessária e universalizante, é preciso considerar o "princípio da dignidade humana”. Kant ([1763] 1966) afirmou que o homem não é ou não deve ser um meio para os outros, mas um fim para si mesmo. O que implica em considerar a alteridade do "eu" que pensa mas também o estatuto do "nós", dirigidos pelos clamores do presente, dos eventos que nos clamam. Se a Filosofia se pensa desde a intempestividade, ela se erige também desde o que a constitui presentemente. Presente não diz respeito à presença, mas aos eventos que nos convocam e obrigam, aos vazios que nem sabemos como completar. Ou seja, de um ponto de vista moral, é como se todos nós, ao menos os habitantes habituais do assim denominado Ocidente, tivéssemos uma concepção do conviver (mit-leben, diria Ferenczi) que devesse implicar sempre a consideração da alteridade e de seus apelos diferenciados; e que nos constituíssem simultaneamente. O que se chama de "nós", desta perspectiva tão bem elaborada por Foucault ([1983] 1994), é mostrar como se vive desde sempre em coletivo e afirmando valores de alcance e saber universais ${ }^{3}$. Mesmo quando tais valores se constituem de impossibilidades práticas: a axiologia psicanalítica se afirma desde impossibilidades que, apesar disto, devem se reafirmar, insistentemente.

Por isto, erigir um "nós" (mostrei ou indiquei como o "nós" se produz de modo inintencional; erigir não é um ato intencional) obriga para além de conjunçôes e encontros convergentes. Se nos vemos levados a pensar o que nos constitui como "eu" e "nós", e se isto impóe um novo estatuto para se elaborar o "nós", a Psicanálise pensou, num modo trágico e cético, uma cisão para a constituição do "nós", de modo radicalmente diferente; com a obra do psicanalista húngaro Sandor Ferenczi (1873-1933), no que ele chamou de "identificação com o agressor" (Ferenczi, [1932] 1982). A criança ama os adultos; ela o faz no registro da ternura e é por eles (adultos) necessariamente atraída e determinada, pois o amor é causa maior e emergencial de acolhimento, proteção e prazer. O homem é um animal prematurado e depende dos cuidados dos outros, bem como de suas tecnologias, para sobreviver, existir e devir. A destinação (Schicksal) da criança é ser capturada 
e ela deve, por isto, ao lado da busca e afirmação de prazer, se identificar positivamente e introjetar os objetos que lhe causem tais sentires. Tais objetos são os adultos e as tecnologias que lhes são inseparáveis.

\section{O ACOLHIMENTO É INDISSOCIÁVEL DA PROTEÇÃO: O TRÁGICO NOS HUMANOS}

Os adultos querem e precisam incorporar a criança, se apropriar dela para incluí-la, capturá-la apaixonadamente. Daí a identificação da criança com o agressor, pois o amor recíproco dos adultos é pleno de sentimentos de apropriação sexual da criança, enquanto a criança responde ainda sem o princípio de realidade, na busca dispersiva da ternura e da entrega ao prazer absoluto e indiferenciado. Diferentemente do que pensam alguns, a criança não é e nem deixa de ser inocente acerca da valorização de tais atos, pois eles são um corolário de sua prematuração.

A isto se acrescenta o medo infantil da ação dos adultos, o que leva as crianças a se submeterem a eles. Tal duplo movimento, que é também investido pela criança, é por ela introjetado, para que possa fazer parte, posteriormente, de sua realidade de adultos.

O que importa nesta observação, de um ponto de vista científico, é a hipótese de que a personalidade ainda fragilmente desenvolvida reage ao brusco desprazer [causado pela submissão não-recíproca aos adultos, de quem vem uma "resposta" inteiramente distinta da pergunta infantil], não pela defesa, mas pela identificação angustiada e a introjeção de quem a ameaça ou agride (Ferenczi, [1932] 1982: 131).

A criança agredida é o próximo agressor: não se trata de um destino de agressor mas de uma destinação, desde a precocidade infantil, permanentemente despreparada para as questões adultas; do mesmo modo que o adulto não é jamais preparado para os questionamentos de "sua" criança.

Atenção: não é um fator universal, mas universalizante, um quase-universal que marca a quase totalidade das relações humanas, subjetivadas ou não. Antes que algum filósofo antifreudiano e apressado replique, isto se dá não por alguma estrutura psíquica universal, mas pela repetição, pois todo adulto é devir criança: tal é o devir da criança, tornando-se adulta, o eterno retorno do Mesmo. Nos fazeres e linguagens humanas, para a constituição (ou não) dos processos de subjetivação, ninguém nasce grande como os adultos (deve-se reler e meditar "O curioso caso de Benjamin Button” de Scott Fitzgerald -1896-1940 - grande escri- 
tor e gozador de ótimo senso, para reaprender a importância etológica das medidas corporais humanas) $)^{4}$.

Por outro lado, este ser menor intervém sempre na formação imaginária de sua constituição posterior em ser grande ou maior, adulto. Como eu próprio, freudiano irredutível, já ensinei anteriormente numa homenagem a Gilles Deleuze (1993):

Ser criança não é apenas obedecer aos poderes, mas exercício imanente de potências. Quando se considera a criança cronologicamente, ela devirá em regimes de forças diferentes. Ensaia caminhos diferenciados, pois "as forças são inseparáveis de uma espontaneidade e de uma produtividade que tornam possível seu desenvolvimento sem mediação, ou seja, sua composiçãao" (Deleuze, 1993:7). Se toda criança já é uma multitudo, pela diferença de suas forças, como se constitui o inconsciente? Não é algo prévio, substância que se trataria de deduzir e mostrar sua incidência num corpo que ela, criança, habitaria. Como também não é um sistema que a criança desconhecesse e que a determinaria. Inconsciente é um encontro de investimentos (Besetzungen) libidinais diferenciados. Ao invés de se determinarem desde um estado originário e central, um Urstaat que captura o que lhe é possível, crianças não se submetem ao poder central ou aos poderes de família, mas são potências devindo. Diferentemente de um poder sedentário e hierarquizante, são potências nômades, insistentemente repetidas; vagabundeando sobre seus próprios corpos, corpos estes que elas mesmas ajudam a fabricar (Katz, 1996).

\section{DIFERENÇAS DE MUITAS ORDENS}

Nos humanos e nos animais vertebrados em geral não é indiferente ser pequeno ou maior: isto constitui as experiências infantis de ser e marcam, para sempre, o ser humano do homem. Não há continuidade entre os seres pequenos e os adultos, ensinou Freud e corroborou Kafka ([1919] 2004) na sua Carta ao Pai; bem como não há descontinuidade completa. $\mathrm{O}$ adulto permanece como criança agredida e se torna agressor, por sua vez. Esta é uma grande contribuição freudiana para a formação do que é o Humano e atinge os setores de quase todas as relações sociais, culturais, políticas etc.

Antes de outros, Freud mostrara que a memória de lembrar não é fixa e determinada, mas opera pela convergência de dois modos diferenciados. Um, através da inscrição dos signos de percepção, pelas associações sincrônicas; outro, através da reinscrição do que não pode ser traduzido no momento de sua passa- 
gem de uma inscrição a uma outra. Ele recusa a existência de uma seqüência temporal que fosse o topos da memória, que marcasse um cimo que determinaria ou que organizasse a memória e "sua" moral. Ou seja - o que nos interessa para pensar a "U" niversalidade com Freud -, as inscrições se fazem em registros diferenciados e uma não supera a outra.

Ferenczi ([1932] 1982), por sua vez, mostrou que essas primeiras impressões sensoriais causam prazer na criança e que esta procura reproduzi-las erogenicamente, num registro que sua consciência desconhece - e que fracassa permanentemente -, mas que tal fracasso obriga também à procura do Mesmo, repetindo-o. Freud ([1921] 1969) já mostrara como isto se dá, pois se o psiquismo coexiste com e é obrigado a cortes e transgressões, rupturas e descontinuidades, há várias posições coexistentes e inseparáveis do Eu por relação ao Outro. Os outros/Outro têm para com o Eu estatutos diferenciados, conjuntivos e simultaneamente excludentes, de opositor e ajudador (Helfer), modelo e objeto.

Esta cisão ferenczianamente postulada entre a criança múltipla e a multiplicidade afetivamente diferenciada dos adultos constitui o pensamento e a emergência do "nós". Não há costura possível entre registros que convergem mas que não têm uma origem única: no humano não há origem que marque o "ser humano" desde ser criança até ser adulto (supondo dois "seres de idade" bem distintos). As rupturas constituem indissociavelmente o psiquismo e as (ditas) identificações negativas se processam nos psiquismos, insistentemente.

Enquanto opositor (Gegner), o Outro procura (em linguagem mais direta) comer o Eu, fagocitá-lo, busca e visa ampliar seu próprio eu às custas de qualquer operação, especialmente a que visa incorporar e destruir gratuitamente o Eu de outrem, um eu qualquer (inclusive o que se chama de "próprio", um Si). Freud já enfrentara antecipadamente o questionamento futuro de Ferenczi, pois as discursividades permitem as unificações, mas também obrigam a decomposição e a destruição. Identificar-se com outros é um modo de assimilá-los e sobreviver. Tais outros se apresentam sob várias e diferenciadas perspectivas, inclusive a do querer assimilar quem se identifica com eles: isto é parte necessária dos modelamentos humanos. Este é o preço da identificação, que não é uma assimilação imagética ou representacional inocente qualquer, uma representação empírica.

Este é um argumento psicanalítico para formular a questão da Universalidade e sua impossível conjunção. Da permanente crueldade na produção do que se denomina o fazer(-se) humano 5 . Portanto, é preciso saber que não há regras específicas para as relações entre indivíduos e povos, países e nações. Pois tais regras se constituem, também e necessariamente, de rupturas, vazios, intervalos, regras de regras... 


\section{INDIVÍDUOS EM TRÂNSITO PERMANENTE}

Haveria que considerar uma categoria que não se enquadra, decididamente, na DUDH. São os sem pouso, no interior de um país ou entre países. Tais paisanos móveis têm estatuto diferenciado e devem ser objeto de atenção dos mais preparados para o assunto. Mas indico a questão, como dificuldade para pensar uma Universalidade de direitos humanos. No Brasil, os migrantes nordestinos, que vão de um não-país a outro, que constituem a massa de trabalhadores rurais escravizados e dos moradores empobrecidos das favelas (que se distinguem entre si). Na Europa, os migrantes africanos, caçados também pelas leis emitidas em junho de 2008, ilegalizando-os definitivamente, prendendo-os antes de expulsálos, separando pais de seus filhos, perseguindo-os sem cessar. Além do incremento de atos populares contra ditos estrangeiros, da parte dos países que constituem a União Européia, os mesmos povos que outrora sofreram perseguições semelhantes, há não mais do que setenta anos: Hitler se impõe, enquanto estatuto legiferante e determinador dos simbólicos e fazeres agressores europeus. $\mathrm{O}$ que na Europa pós 1945 foi considerado crime contra a Humanidade é hoje regra jurídica. Não menos diferente, mas ainda um pouco mais suave, é a existência dos cerca de 26 milhões de imigrantes latinos ditos ilegais nos Estados Unidos, perseguidos por duras legislações. Que palavras ouvimos da ONU?

Direitos minoritários, de que modo, se as regras são, desde a perspectiva filosófica ampliada, altamente ilegais, mas juridicamente estabelecidas? Se alguns filósofos, desde uma elevada e impossível dignidade, procuram estabelecer um caráter quase universalizante acerca da hospitalidade, do acolhimento amplo dos diferentes, como isto se faz na concretude? Pois a chamada Razão não se constitui unicamente nas modalidades conjuntivas e tem regras distintas da eficácia dos poderes, eis o que aprendemos para acompanhar a labilidade da DUDH. Agora, fala você, leitor.

\section{REFERÊNCIAS BIBLIOGRÁFICAS}

Agamben, G. (2003). A zona mortal da Lei. Em Folha de São Paulo, 16/03/03.

- (2004). Estado de exceção. São Paulo: Boitempo.

Conrad, J. (1902). Heart of Darkness. Delaware: Prestwick House Inc., 2004.

Derrida, J. (2000). États d'âme de la psychanalyse. Paris: Galilée.

Deleuze, G. Prefácio ao livro de Antônio Negri $A$ anomalia selvagem. Poder e potência em

Spinoza. Rio de Janeiro: Editora 34. 
Ferenczi, S. (1932). Confusion de langue entre les adultes et l'enfant. Le langage de la tendresse et de la passion. Em Psychanalyse. Oeuvres complètes. Tome IV: 19271933 (pp. 125-135). Paris: Payot, 1982.

Foucault, M. (1966). L'homme est-il mort? Em Dits et écrits I (1954-1988) (pp. 540544). Paris: Gallimard, 1994.

. (1983). Qu'est-ce que les Lumières? Em Dits et écrits IV (1980-1988) (pp. 679-688). Paris: Gallimard, 1994.

Freud, S. (1921). Psicologia de grupo e análise do ego. Obras completas, ESB, v. XVIII. Rio de Janeiro: Imago, 1996.

Kafka, F. (1919). Carta ao Pai. Porto Alegre: L\&PM, 2004.

Kant, I. (1763). Versuch den Begriff der negativen Groessen in die Weltweisheit einzuführen. Vorkritische Schriften bis 1768. Darmstadt: Wissenschaftliche Buchgesellschaft, 1996.

Katz, C. (1996). Texto em homenagem a Giller Deleuze. Colégio Internacional de Estudos Filosóficos Transdisciplinares. Rio de Janeiro, UERJ, não publicado.

\section{Notas}

1 Ver Jornal Mundo Lusiada: http://mundolusiada.com.br/POLITICA/poli266_ago07.htm. Acessado em: 30/08/2007.

2 Lembremo-nos do que aprendemos com Xenófanes de Colofão (577-480 a.C., vinte e seis séculos atrás): se bois, cavalos e leões tivessem mãos, reproduziriam os deuses com os aspectos de seus corpos animais. As figuras divinas são antropomorfizadas e Deus é o antropomorfizado maior.

3 Lembremo-nos de que Kant ([1763] 1966) inicia sua resposta à questão sobre o que é o Iluminismo (Was ist Aufklärung) pensando simultaneamente o estatuto da Haskalá (que corresponde ao Iluminismo) judaica e seu direito (e dos judeus em geral) à cidadania e ao pensamento alemães. Ou seja, uma questão que corresponde ao presente então dos vários pensadores e seu estatuto de "nós".

4 “The Curious Case of Benjamin Button" é um conto de 1922 de Scott Fitzgerald. Encontrase disponível, no inglês original, em: http://www.readbookonline.net/read/690/10628/. Acessado em: 02/09/2008

${ }^{5}$ Como ensinou Jacques Derrida (2000), a crueldade é um permanente constituir do Humano. A Psicanálise freudiana reconhece e conhece as várias modalidades de ser, pulsões de apoderamento e destruição, pulsões de morte e de agressividade, necessidade expansiva de poder (Machtbedürfnis), mal-estar, desamparo, a capacidade permanente e incisiva de disjunção pulsional, a impossibilidade de o psiquismo recusar permanentemente a crueldade da vida, a 
expansão psíquica insistente e incessante, a disrupção permanente nos indivíduos, a dissensão incessante das instituições sociais - assim se posiciona o Inconsciente. Os modos de subjetivação, em sua maneira atemporal, se fazem sob tal influxo. Não há algum ser permanente que se deixasse capturar através de caminhos serenos, ou uma substância que garantisse e ordenasse os conceitos e categorias: temos e somos uma afirmação permanente de tal dilaceramento.

Recebido em 17 de janeiro de 2008 Aceito para publicação em 02 de setembro de 2008 